\title{
FRONTEIRAS DA EDUCAÇÃO: alunos indígenas e imigrantes em tempos de aulas remotas, um olhar reflexivo ao projeto "@prendendoemcasabv"
}

\section{FRONTERAS DE LA EDUCACIÓN: estudiantes indígenas e inmigrantes en tiempos de enseñanza a distancia, una mirada reflexiva al proyecto “@prendendoemcasabv"}

\section{FRONTIERS OF EDUCATION: indigenous and immigrant students in times of remote classes, a reflective look at the “@prendendoemcasabv project"}

\author{
Elândia Gomes Araújo ${ }^{1}$ \\ https://orcid.org/0000-0001-9205-8100 \\ Enia Maria Ferst ${ }^{2}$ \\ https://orcid.org/0000-0003-3509-3609 \\ Alessandra de Souza Santos 3 \\ https://orcid.org/0000-0001-5077-8484
}

\section{Resumo}

O presente artigo resultou de pesquisa realizada a partir do material do Projeto Aprendendo em Casa BV, da Secretaria Municipal de Boa Vista - SMEC, cujo objetivo foi identificar se há no projeto em tela, atividades voltadas ao ensino do estudante imigrante e/ou indígena que ainda não domina a Língua Portuguesa, numa perspectiva de inclusão desses discentes. $O$ impulso em realizar o

\footnotetext{
${ }^{1}$ Mestranda do Programa de Pós-Graduação em Educação PPGE/UERR-IFRR. Especialista em Educação: Métodos e Técnicas de Ensino - IFRR e em Língua Portuguesa e Literatura - UERR. Membro dos grupos de pesquisas: Paulo Freire e Educação de Jovens e Adultos na Amazônia Setentrional e Línguas em contexto de diversidade linguística. E-mail: elandiaraujo@gmail.com

2 Doutora em Educação em Ciências e Matemática - REAMEC/UFMT. Professora do Programa de PósGraduação em Educação PPGE/UERR-IFRR. Desenvolve pesquisas na temática de ensino de Ciências nos Anos Iniciais do Ensino Fundamental, formação de professores e CTS. E-mail: mestreenia@gmail.com

${ }^{3}$ Doutora em Linguística - UnB. Professora do Programa de Pós-Graduação em Educação PPGE/UERR-IFRR. Pesquisa as línguas humanas (patologias, aquisição e aprendizagem), contato linguístico e formação de professores de línguas materna e/ou segundas línguas. E-mail: profalessandradess@gmail.com
}

Como referenciar este artigo:

ARAÚJO, E. G.; FERST, E. M.; SANTOS, A. S. Fronteiras da educação: alunos indígenas e imigrantes em tempos de aulas remotas, um olhar reflexivo ao projeto "@prendendoemcasabv". Revista Pedagógica, v. 23, p. 1-23, 2021. 
trabalho sobre esta temática parte do interesse em verificar se houve inclusão desses alunos no ensino remoto nas escolas da rede municipal, a fim de identificar como se dá este processo e quais as metodologias utilizadas. Com isso, destacamos questões relacionadas às novas formas de ensinar, remotamente, como a necessidade de se conter a pandemia causada pelo novo coronavírus (SARS-CoV-2). Para desenvolver esta investigação utilizou-se como metodologia a pesquisa documental, por meio de análise das atividades do Projeto Aprendendo em Casa BV, concomitantemente com a abordagem qualitativa, pois buscamos averiguar se existiu a atenção em elaborar atividades capazes de inserir esse público que não fala a língua portuguesa como língua materna. Os resultados apontam que não houve demonstração de cuidados específicos com os alunos imigrantes, pois todas as atividades disponibilizadas são elaboradas em língua portuguesa. Nesse mesmo sentido os discentes indígenas também foram deixados à margem, pois somente depois de decorridos mais de dois meses do início dessa proposta é que disponibilizaram atividades nas línguas indígenas maternas Macuxi e Wapichana, todavia tratando essas atividades como complementares, evidenciando o caráter monolíngue existente em nossas escolas.

Palavras-chave: Aprendendo em Casa BV. Alunos imigrantes. Alunos indígenas. Ensino remoto. Município de Boa Vista/RR.

\section{Resumem}

Este artículo fue el resultado de una investigación realizada utilizando el material del Proyecto “@prendendoemcasabv", de la Secretaría Municipal de Boa Vista - SMEC, cuyo objetivo fue identificar si existen actividades en tal proyecto dirigidas a la enseñanza de inmigrante y / o estudiantes indígenas que aún no dominan el idioma portugués, en una perspectiva de incluir a estos alumnos. El impulso para trabajar en esta temática se enmarca en el interés por verificar si estos estudiantes fueron incluidos en la enseñanza a distancia en las escuelas municipales, con el fin de identificar cómo se desarrolla este proceso y qué metodologías se utilizan. Con ello, destacamos cuestiones relacionadas con las nuevas formas de enseñar, la educación a distancia, como la necesidad de contener la pandemia provocada por el nuevo coronavirus (SARS-CoV-2). Para la realización de esta investigación se utilizó como metodología la investigación documental, a través del análisis de las actividades del Proyecto "@prendendoemcasabv", en concomitante con el abordaje cualitativo, ya que buscamos constatar si hubo atención en desarrollar actividades capaces de insertar este público no hablante del portugués como lengua materna. Los resultados muestran no hubo un cuidado específico para los estudiantes inmigrantes, ya que todas las actividades disponibles están elaboradas en portugués, en el mismo sentido los estudiantes indígenas también quedaron al margen, porque solo después de transcurridos más de dos meses desde el inicio de esta propuesta fue que pusieron a disposición las actividades en lenguas indígenas Macuxi y Wapichana, pero tratando estas actividades como complementarias, mostrando el carácter monolingüe que existe en nuestras escuelas.

Palabras clave: “Aprendendo em Casa BV”. Estudiantes inmigrantes. Estudiantes indígenas. Educación a distancia. Municipio de Boa Vista/RR.

\section{Abstract}


This article is the result of a research performed out of the "Aprendendo em Casa BV" Project, from Boa Vista's Municipal Secretary, whose objective was to identify if there is, in the displayed project, activities aimed at teaching the immigrant or indigenous student who do not yet master the Portuguese Language, within an inclusive perspective towards these students. The impulse to work on this theme begins with an interest in verifying whether these students are included in remote education in municipal schools, so one can identify the process and methodologies. As such, we highlight questions related to new ways of teaching, remotely, with the need to contain the new coronavirus (SARS-CoV-2) pandemic. In order to develop this investigation, a documentary research was used as methodology, through the analysis of the activities of the "Aprendendo em Casa BV" Project, concomitant to a qualitative approach, for we seek to ascertain whether there was attention towards developing activities capable of receiving this population who does not speak Portuguese as a mother language. The results point that there was not demonstration of specific care with immigrant students, for all the activities available are elaborated in Portuguese. Equally,the indigenous students were marginalized, once the activites in mother language Macuxi and Wapichana were made available only two months later, still considered as complementary activities, evidencing the monolingual character of our schools.

Keywords: "Aprendendo em casa BV". Immigrant students. Indigenous students. Remote teaching. Municipality of Boa Vista/RR.

\section{INTRODUÇÃO}

Em decorrência da pandemia causada pelo novo coronavírus (SARS-CoV-2), detectado e identificado inicialmente na China, na cidade de Wuhan, as escolas de todo o Brasil e também de muitos países foram fechadas como medida de segurança e também como ações de contenção da expansão do vírus, conforme recomendado pela Organização Mundial de Saúde (OMS). O isolamento social, instrução dos órgãos de saúde pública, levou à suspensão temporária das aulas.

Diante desse quadro pandêmico e com o intuito de manter as atividades e disciplinas escolares, as instituições educacionais recorreram às plataformas virtuais, em um modelo de ensino à distância 4 , chamado nesse cenário de "ensino remoto5" ou

\footnotetext{
${ }^{4}$ Onde são utilizadas ferramentas, meios e tecnologias de informação e comunicação, pessoal qualificado, além de políticas de acesso e acompanhamento e avaliação compatíveis. "Aulas no formato EaD, possui metodologia de ensino e materiais específicos para esta modalidade, com aulas gravadas previamente, que o aluno assiste em uma plataforma adequada para o formato". (CESUSC, 2020, s/p).

5 Já no "Regime Remoto Temporário", formato que foi adotado excepcionalmente, neste momento, as aulas acontecem ao vivo, por videoconferência, nos dias e horários habituais, com o auxílio de ferramentas tecnológicas (TIC's), e são disponibilizadas em arquivos gravados. (CESUSC, 2020, s/p).
} 
“ensino não presencial" ". Nesse sentido o município de Boa Vista publicou o Decreto Municipal $n^{\circ}$ 033-E/20207 , de 16 de março de 2020, dispondo sobre medidas temporárias e emergenciais de prevenção de contágio por essa doença, regulamentando dessa forma a suspensão de atividades educativas presenciais neste município, a partir do dia dezessete daquele mesmo mês e ano.

Com o fechamento das escolas e suspensão das aulas presenciais, a propositiva da Prefeitura Municipal de Boa Vista - PMBV, por meio da Secretaria Municipal de Educação e Cultura - SMEC foi a utilização do Projeto Aprendendo em Casa BV, propagado e distribuído pelo Portal $^{8}$ da PMBV e pela página da rede social Instagram no perfil “@aprendendoemcasabv”, com disponibilização diária das atividades correspondentes ao ano escolar de cada criança. Além disso houve o acompanhamento remoto das escolas municipais pelo aplicativo de mensagens instantâneas WhatsApp entre os professores de cada turma e os pais ou responsáveis no envio das atividades em questão, conforme mensagem do projeto no site da Prefeitura Municipal de Boa Vista.

[...] O Projeto "Aprendendo em Casa BV" contempla atividades extracurriculares elaboradas por especialistas em Educação, Gestão Escolar e professores voluntários da Rede Municipal de Ensino. As atividades disponíveis no projeto "Aprendendo em Casa BV" são elaboradas para cada etapa e modalidade de ensino, quais sejam: Educação Infantil (creche e pré-escola); Ensino Fundamental ( $1^{\circ}$ ao $5^{\circ}$ ano); Educação de Jovens e Adultos ( $1^{\mathrm{a}}$ a $4^{\mathrm{a}}$ série) e Educação Especial, contemplando as disciplinas de Arte, Educação Física e Língua Materna Macuxi e Wapichana (RORAIMA, 2020, s/p.).

O referido projeto iniciou na primeira semana de abril do ano de 2020, por meios digitais, como tentativa de viabilizar ${ }^{10}$ o ensino e a aprendizagem, ainda que remotamente, para que as crianças seguissem aprendendo durante o período de isolamento e distanciamento social, conforme destacado em matéria jornalística do jornal Roraima em Foco.

\footnotetext{
${ }^{6}$ As "atividades não presenciais entende-se, neste parecer, aquelas a serem realizadas pela instituição de ensino com os estudantes quando não for possível a presença física destes no ambiente escolar". (MEC, 2020).

7 Disponível em: https://www.boavista.rr.gov.br/diario-oficial. Acesso em: 28 jul. 2020.

${ }^{8}$ Disponível em: https://www.boavista.rr.gov.br/aprendendo-em-casa/ Acesso em: 28 jul. 2020.

9 Disponível em: https://www.instagram.com/aprendendoemcasabv/?hl=pt-br. Acesso em: 28 jul. 2020.

${ }^{10}$ Atividades extracurriculares e não obrigatórias, "as aulas e atividades à distância, apresentadas no Projeto Aprendendo em Casa BV para a comunidade escolar, não substituem as aulas presenciais e tampouco seus conteúdos correspondem aos componentes curriculares nacionais". Ver mais em: https://observatorio.prefeitura.boavista.br/paginas/aprendendo-em-casa-bv. Acesso em: 09 out.2020.
} 
[...] Tarefas diárias não são obrigatórias. É importante ressaltar que as atividades virtuais são extracurriculares e não substituirão a proposta curricular presencial. A página está sendo atualizada diariamente, com exceção dos finais de semana e feriados. As atividades também estão disponibilizadas via WhatsApp criados por professores e gestores das escolas e creches municipais (CHAVES, 2020, s/p.).

A utilização desses instrumentos para propor atividades para as crianças em tempos de quarentena tem sido um grande desafio para as secretarias de educação de estados e municípios nos vários rincões do Brasil, fato não diferente em solo roraimense que faz fronteira com dois países com diferenciação linguísticas e culturais e que vem recebendo nesses últimos anos uma grande quantidade de imigrantes, principalmente oriundos do país vizinho, República Bolivariana da Venezuela.

Essa situação pandêmica que levou aulas presenciais para ambientes virtuais, levantou muitas dúvidas para quem nunca estudou por essa modalidade. As dificuldades para a implementação e execução do ensino de forma remota vão desde as mudanças de rotinas e afazeres domésticos, que necessitam ser ajustadas para o acompanhamento e realização das atividades educacionais com as crianças e adolescentes, à falta de acesso à internet e aos meios tecnológicos digitais. Nesse sentido, voltamos nosso olhar aos estudantes imigrantes, na maioria venezuelanos que moram em abrigos mantidos e gerenciados por instituições governamentais e/ou por ONG's, ou ainda aqueles que vivem em situação de rua e também aos alunos indígenas, com compreensão linguística diversa à língua portuguesa.

Neste trabalho buscamos identificar se no material do referido projeto houve a preocupação com a elaboração e posterior execução de atividades voltadas ao ensino, na perspectiva de inclusão, dos alunos imigrantes e/ou indígenas que ainda não dominam a

Língua Portuguesa e quais as contribuições no tocante ao desenvolvimento e aprendizagem desses discentes.

\section{QUE DIZEM AS LITERATURAS SOBRE O “ENSINO REMOTO EMERGENCIAL”?}

Com as medidas em face e na tentativa de se preservar a saúde dos atores das instituições educacionais, foi necessária a mudança da mediação do ensino. Desta forma, o ensino antes realizado de maneira presencial transformou-se em ensino remoto, 
entendido por Hodges et al. (2020, p.6) como: “Ensino Remoto de Emergência (ERE)"11, que é uma mudança temporária para um modo de ensino alternativo devido as circunstâncias de crise".

Ainda nessa discussão, para Behar:

O termo "remoto" significa distante no espaço e se refere a um distanciamento geográfico. O ensino é considerado remoto porque os professores e alunos estão impedidos por decreto de frequentarem instituições educacionais para evitar a disseminação do vírus. É emergencial porque do dia para noite o planejamento pedagógico para o ano letivo de 2020 teve que ser engavetado (BEHAR, 2020, $s / p)$.

Sendo assim, o ensino adotado temporariamente pela SMEC pode ser considerado remoto, pois se diferencia da modalidade de ensino à distância, com aulas que acontecem em espaços diversos à escola. $\mathrm{E}$, mediante esta mudança, professores, alunos e pais e/ou responsáveis tiveram que se adaptar ao novo modo de ensino, por meio de ferramentas e tecnologias digitais, e em específico no Projeto Aprendendo em Casa BV foram utilizados o aplicativo de mensagens instantâneas WhatsApp e a página da rede social Instagram, que, de acordo com Chaves (2020), em outubro de 2020 contava com "mais de 280 publicações e mais de vinte mil seguidores". Essa ferramenta tecnológica vai ao encontro às normas do Parecer homologado pelo Ministério da Educação e o Conselho Nacional de Educação, aprovado em 28 de abril de 2020, que salienta:

[...] a realização das atividades pedagógicas não presenciais não se caracteriza pela mera substituição das aulas presenciais e sim pelo uso de práticas pedagógicas mediadas, ou não, por tecnologias digitais de informação e comunicação que possibilitem o desenvolvimento de objetivos de aprendizagem e habilidades previstas na BNCC, currículos e propostas pedagógicas passíveis de serem alcançados por meio destas práticas (MEC, 2020, p.8).

O método do ensino remoto emergencial ainda é um grande desafio aos profissionais da educação, pois as produções científicas e discussões sobre essa temática são recentes e há também divergências entre os educadores, instituições e órgãos governamentais sobre quais os caminhos a serem percorridos nesse "novo jeito" de estudar e ensinar. Nesse ínterim, o ser humano foi e está sendo desafiado a um processo

\footnotetext{
"Ver mais em: HODGES, Charles; MOORE, Stephanie; LOCKEE, Barb; TRUST, Torrey; BOND, Aaron. Diferenças entre o aprendizado online e o ensino remoto de emergência. Revista da Escola, Professor, Educação e Tecnologia, v. 2, 2020. Disponível em: https://educacaobasicaemfoco.net.br/NumeroAtual/Artigos.html. Acesso em: 09 out. 2020.
} 
constante e contínuo de fazer e refazer o seu próprio conhecimento, fato que não ocorre apenas nesse contexto pandêmico, pois segundo Freire:

[...] Ninguém sabe tudo, assim como ninguém ignora tudo. O saber começa com a consciência do que se sabe (enquanto alguém atua). É sabendo que se sabe pouco que uma pessoa se prepara para saber mais. Se tivéssemos um saber absoluto, já poderíamos continuar sabendo, pois que este seria um saber que não estaria sendo. Quem tudo soubesse já não poderia saber, pois não indagaria. $O$ homem, como um ser histórico, inserido num permanente movimento de procura, faz e refaz constantemente o seu saber (FREIRE, 1983b, p. 47).

A nova situação causada pela Covid -19, a pandemia, trouxe diversos desafios ao ato de ensinar, mas também surgiram inúmeras possibilidades de uso da tecnologia como ferramenta imprescindível para fazer a informação e o conhecimento chegar até os discentes. Todavia, sabemos que as dificuldades de acesso aos meios tecnológicos e digitais estão aquém da grande maioria dos alunos, o que em muitos casos dificulta, senão anula as possiblidades de se efetivar o ensino por este novo formato, o ensino remoto ou não presencial. E essas dificuldades remetem a outros questionamentos, a serem pesquisados em um outro momento, como por exemplo, como vem ocorrendo o ensino remoto nas comunidades indígenas? Os alunos indígenas têm como acessar as plataformas ou os canais digitais disponibilizados pelo Projeto Aprendendo em Casa BV? No momento nosso foco de pesquisa é verificar se o material produzido no referido projeto traz em sua proposta atividades inclusivas, para os alunos imigrantes e/ou indígenas que não têm a língua portuguesa como língua materna.

\section{AS ATIVIDADES DO PROJETO APRENDENDO EM CASA BV E O ENSINO REMOTO, EM LÍNGUA PORTUGUESA, AOS ESTUDANTES IMIGRANTES E/OU INDÍGENAS}

Ao discutirmos a aplicação do Projeto Aprendendo em Casa BV, de forma remota e sobretudo em língua portuguesa, faz-se necessário destacar nosso entendimento sobre língua, vista como interação e prática social, que de acordo com Thurck (2011, p. 6), “[...] é determinada pela interação verbal entre sujeitos híbridos, sociais e históricos [...]. Assim sendo, língua é a habilidade utilizada pelos indivíduos como meio de comunicação em seu convívio social, permitindo a integração, interação e comunicação entre os sujeitos de uma determinada sociedade ou comunidade. 
Neste contexto, vale salientar a crescente presença de estudantes imigrantes nas salas de aula brasileiras, no caso de alunos venezuelanos, destaca-se o Estado de Roraima, em decorrência de sua situação geográfica de fronteira. O aumento significativo de matrículas desses discentes é destacado por Zambrano:

[...] as escolas municipais de Boa Vista atendem $14 \%$ dos alunos estrangeiros (SMEC, 2020), principalmente venezuelanos, segundo dados de fevereiro de 2020. E as escolas estaduais tinham, em maio de 2019, 4.123 alunos Venezuelanos e 72.471 estudantes brasileiros (SEED, 2020), o que corresponde a mais de 5\% de falantes de espanhol presentes na rede estadual de ensino. De acordo com a nota da Secretaria de Educação de Roraima, estima-se que o número de venezuelanos na rede estadual de ensino em 2020 ultrapassou 6 mil alunos, enquanto em 2015 eram poucos mais de 100 alunos de nacionalidade venezuelana. No município de fronteira, Pacaraima, a rede municipal de educação está atendendo cada vez mais estudantes venezuelanos, alcançando até $48 \%$ do total de alunos em 2020, segundo dados da Secretaria Municipal de Educação de Pacaraima (ZAMBRANO, 2020, p. 8, tradução nossa).

Ainda sobre esse contexto de imigração, Diniz e Neves (2018, p. 88) chamam a atenção para "[...] o número de crianças e adolescentes estrangeiros que, muitas vezes, têm baixa proficiência na principal - ou mesmo única - língua de instrução das instituições escolares em que são - ou deveriam estar - matriculados". Diante dessa realidade, chamamos a atenção para o fato de que a dificuldade de comunicação é apenas a primeira barreira que o estudante imigrante necessita transpor para estabelecer-se, integrar-se nas escolas de um país com língua materna diversa à sua, situação também experienciada pelos alunos indígenas das várias etnias que também não falam o português como língua originária.

No Brasil, mesmo com o crescente fluxo migratório não há políticas públicas no tocante ao ensino de português para imigrantes. Nesse sentido, Amado destaca que:

Se os governos ainda não atentaram para a necessidade de promover o ensino de português para esses imigrantes, é premente que as universidades, principalmente as públicas, que ministram cursos de Letras, criem programas de extensão universitária e incentivem seus alunos a fazerem estágios nesses programas. As instituições que já têm especialidades em nível de graduação ou pós-graduação em PLE, é mais do que urgente que voltem seus olhos, na pesquisa e no ensino, a esse público que, arrancado de sua terra natal, de sua família, de sua língua, busca neste país uma nova oportunidade de refazimento, de integração, de paz (AMADO, 2013, p. 8).

Da afirmação de Amado (2013) e ainda com base nos dados citados por Zambrano (2020) com relação ao número de matrículas nas escolas públicas de Roraima, evidencia- 
se a necessidade de estudos nessa área devido à grande inserção de alunos imigrantes nas escolas de todo o país, e em Roraima chegando a "alcançar até $48 \%$ do total de alunos em 2020", como é o caso do município de Pacaraima, que faz fronteira com a República Bolivariana da Venezuela. Assim sendo, é premente que o Brasil e também nosso Estado se percebam, enquanto espaço educativo, não de forma monolíngue, mas com ambientes escolares de trocas, de interações linguísticas, culturais, enfim, de saberes múltiplos.

Com a heterogeneidade linguística e cultural percebível no estado de Roraima, nos causa estranheza que o material do Projeto Aprendendo em casa BV desconsidere essas particularidades de nossas salas de aula, uma vez que o ente municipal é ciente da realidade multicultural e multilíngue das escolas de Boa Vista/RR. A escolha de uma dada metodologia ou material didático em detrimento de outros nos faz refletir sobre o porquê da invisibilidade dos estudantes imigrantes e indígenas. E corroborando com essa discussão Silva e Zambrano asseveram que:

[...] é importante compreender os imigrantes como pessoas iguais a nós, que possuem conhecimentos a serem compartilhados, não como subalternos que estão na sala de aula apenas para aprender aquilo que os professores acham que é mais urgente para sua inserção na sociedade (SILVA; ZAMBRANO, 2021, p. 216).

E em relação aos docentes, esses autores chamam a atenção para o tradicionalismo monolíngue em suas formações, destacando a necessidade de:

[... ] uma política linguística formativa permanente e a longo prazo, que considere as especificidades linguísticas e culturais da localidade e dos imigrantes forçados, para propor reflexões epistemológicas decoloniais que possam atravessar os projetos globais até chegar às histórias locais na formação profissional dos professores de línguas em Roraima (SILVA; ZAMBRANO, 2021, p. 219).

Essa não atenção - ou silenciamento - dos imigrantes no tocante ao material do “Aprendendo em casa" também é direcionada aos estudantes indígenas, pois mesmo com a aprovação da Lei $n^{\circ} 11.645 / 08$ que tornou obrigatório o estudo da história e cultura afrobrasileira e indígenas nas escolas, essa norma constitucional ainda necessita de uma efetivação mais consistente. O material do projeto aqui em análise, até disponibiliza atividades nas línguas maternas Macuxi e Wapichana, mas esse material só começou a ser elaborado nessas línguas quando o projeto já estava na $11^{\text {a }}$ semana de execução e mesmo 
assim, trata essas atividades como "complementares", evidenciando o que destaca Candau:

A cultura escolar predominante nas nossas escolas se revela como "engessada", pouco permeável ao contexto em que se insere, aos universos culturais das crianças e jovens a que se dirige e a multiculturalidade das nossas sociedades (CANDAU, 2002, p. 53).

Ainda sobre o ensino de português para imigrantes, como já explicitado não há políticas públicas nesse sentido, e as ações isoladas de Instituições de Ensino Superior IES ou Organizações não governamentais - ONG's são voltadas ao público adulto, cabendo às crianças aprenderem no contato e interação diária com seus colegas de escolas e com seu corpo docente, situação essa comprometida devido ao isolamento e distanciamento social. Quanto ao acesso das crianças às nossas redes de ensino, São Bernardo destaca que:

No que concerne as crianças, há o direito por parte das/os refugiadas/os de matricularem seus filhos na escola pública. Nesse ambiente, as/os pequenas/os imigrantes aprendem a língua pelo convívio no contexto social de interação com outras crianças, em consequência de não contarem com apoio pedagógico especializado ou cursos específicos para a aquisição da língua (SÃO BERNARDO, 2016, p. 40).

As crianças têm o direito constitucional de se matricularem em nossas escolas públicas e o Brasil, e em especial o Estado de Roraima vem cumprindo essa norma legal. Mas como assevera São Bernardo, cabe a elas aprenderem a língua de nosso país por meio de trocas, no convívio social e interação com as outras crianças. Mas, com o quadro pandêmico elas deixaram de ter esses momentos de trocas e passaram a estudar em suas casas ou nos abrigos onde vivem, sob a orientação e com a ajuda de seus país, também imigrantes, por meio das atividades do Projeto Aprendendo em Casa BV, com todo o seu material escrito ou falado produzido em língua portuguesa, sem preocupação com a inclusão linguística desses discentes, fato que certamente acarreta dificuldades quanto à resolução de tais atividades.

Diante desse contexto, para desenvolver esta investigação utilizou-se como metodologia a pesquisa documental, tomando como materialidade de análise as atividades do Projeto Aprendendo em Casa BV, no período de abril a setembro de 2020. A abordagem utilizada foi a do tipo qualitativa, pois procurou-se verificar se houve a 
preocupação na elaboração das atividades propostas com esse projeto em relação aos estudantes imigrantes e/ou indígenas que ainda não dominam a Língua Portuguesa, possibilitando a esses discentes não apenas os direitos de acesso, mas também de permanência e desenvolvimento de suas atividades educativas, com respeito à diversidade social, cultural e linguística em que estão inseridos.

Ainda sobre o tipo de pesquisa, segundo Minayo:

[...] A pesquisa qualitativa responde as questões muitos particulares. Ela se preocupa, nas ciências sociais, com o nível de realidade que não pode ser quantificado, ou seja, ela trabalha com universo de significado, motivos, aspirações, crenças, valores e atitudes, o que corresponde a um espaço mais profundo das relações dos processos e dos fenômenos que não podem ser reduzidos à operacionalização de variáveis (MINAYO, 1995, p. 21-22).

A metodologia de pesquisa documental, segundo Marconi \& Lakatos (2003) é distinta da bibliográfica, mesmo que as duas utilizem documentos, o que as diferenciam é a fonte dos documentos. Na primeira trabalha-se com as fontes primárias, com documentos ainda sem tratamento analítico, como é o caso das atividades do Projeto Aprendendo em Casa BV, enquanto na segunda, tem como fonte de pesquisa os documentos já analisados, parte de uma bibliografia já pública sobre uma determinada temática.

Assim sendo, na perspectiva de tentar entender o contexto educacional local, diante da pandemia da Covid 19 e com olhar analítico em relação à suspensão das aulas presenciais, nos debruçamos sobre o material do Projeto Aprendendo em Casa BV lançado pela PMBV por meio da SMEC com o objetivo de oferecer aos estudantes da rede municipal atividades opcionais para o desenvolvimento educacional. Essas atividades foram consideradas até dezembro de 2020 como extracurriculares, não obrigatórias e não seriam contabilizadas na carga horária, tampouco substituiriam as atividades presenciais.

O projeto foi iniciado, de maneira remota, com material proposto aos estudantes da Educação Infantil, Educação Especial, Educação Especial - Deficiência Auditiva e Educação Especial - Deficiência Visual. As atividades para os alunos do Ensino Fundamental, do $1^{\circ}$ ao $5^{\circ}$ Ano, com os componentes do conhecimento em Língua Portuguesa, Matemática, Ciências, Geografia e História iniciaram na segunda semana e para EJA - Ensino Fundamental anos iniciais foram disponibilizadas a partir da terceira 
REVISTA

PEDACE

Revista do Programa de Pós-Graduação em Educação da Unochapecó

ISSN 1984-1566 (on-line) ISSN 1415-8175 (impressa)

semana. Os componentes de conhecimento em Artes e Educação Física tiveram as atividades disponibilizadas a partir da sexta semana. Já as atividades nas Línguas Indígenas Maternas Macuxi e Wapichana, para os discentes indígenas que residem e estudam nas zonas rurais da capital, só começaram a fazer parte desse projeto a partir da $11^{\mathrm{a}}$ semana de sua execução, fato que suscita dúvidas quanto à forma como é vista a educação para esse grupo de estudantes, conforme tabela a seguir:

Tabela 1 - Início das atividades desenvolvidas pelo Projeto Aprendendo em casa BV

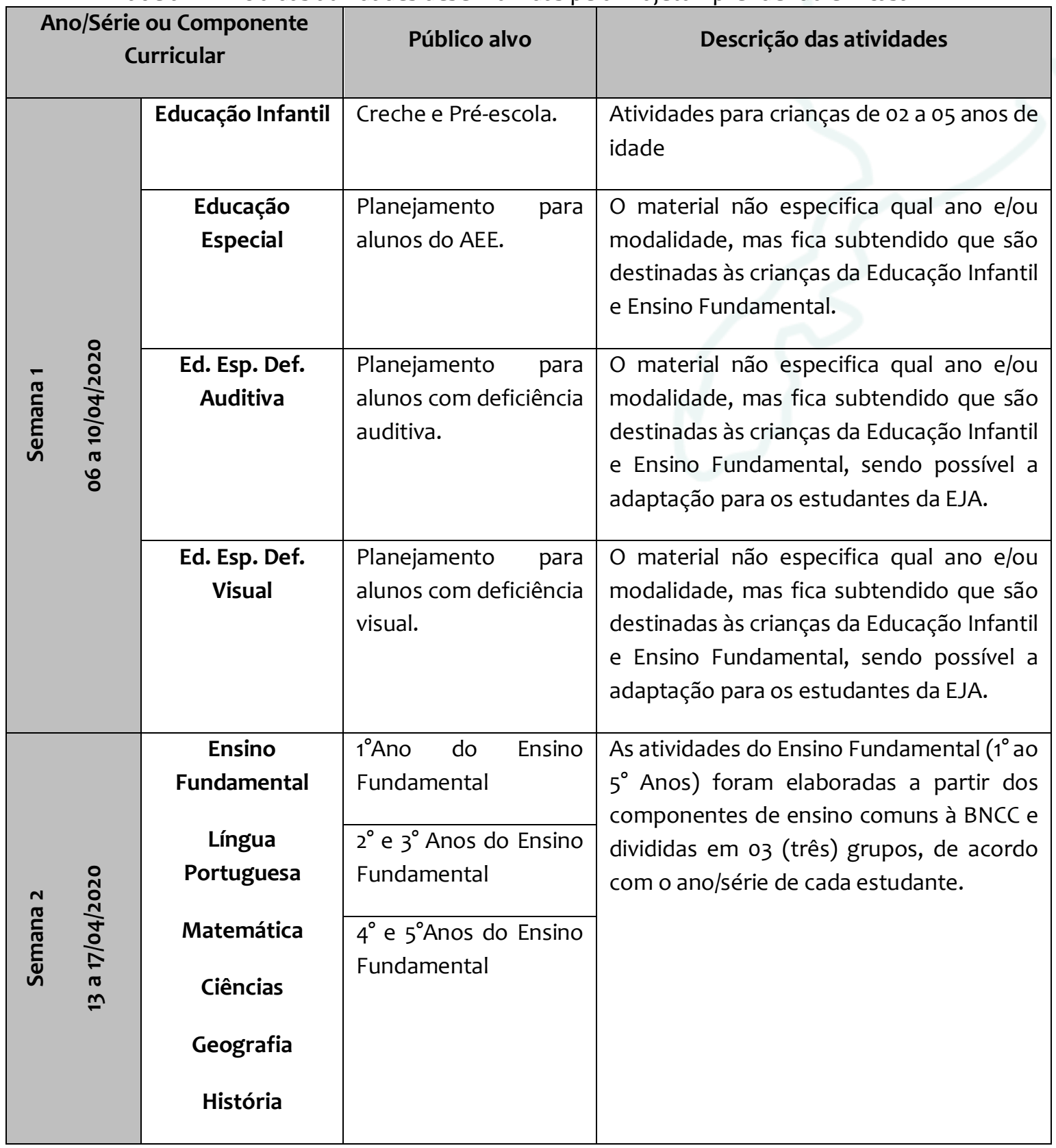




\begin{tabular}{|c|c|c|c|c|}
\hline \multirow{3}{*}{ 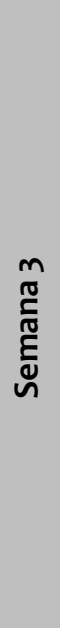 } & \multirow{3}{*}{  } & \multirow{3}{*}{\begin{tabular}{|c} 
Educação de \\
Jovens e Adultos \\
- EJA \\
Língua \\
Portuguesa \\
Ciências \\
Humanas e da \\
Natureza \\
Matemática \\
Ciências
\end{tabular}} & $\begin{array}{l}\text { EJA }- \text { Ensino } \\
\text { Fundamental }-1^{\mathrm{a}} \text { e } 2^{\mathrm{a}} \\
\text { Série }\end{array}$ & \multirow{3}{*}{$\begin{array}{l}\text { As atividades da EJA - Ensino Fundamental } \\
\text { (Anos Iniciais) foram elaboradas a partir } \\
\text { dos componentes de ensino comuns à } \\
\text { BNCC e divididas em } 02 \text { (dois) grupos, de } \\
\text { acordo com o ano/série de cada estudante. }\end{array}$} \\
\hline & & & $\begin{array}{l}\text { EJA }- \text { Ensino } \\
\text { Fundamental }-3^{\mathrm{a}} \text { e } 4^{\mathrm{a}} \\
\text { Série }\end{array}$ & \\
\hline & & & & \\
\hline \multirow{2}{*}{ 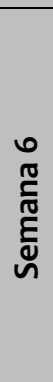 } & \multirow{2}{*}{ 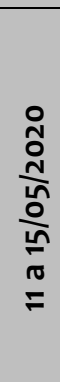 } & \multirow[t]{2}{*}{$\begin{array}{c}\text { Componentes } \\
\text { Artes e Educação } \\
\text { Física }\end{array}$} & $\begin{array}{l}\text { Educação Infantil } \\
\text { Ensino Fundamental } \\
\left(1^{\circ} \text { ao } 5^{\circ} \text { Anos }\right)\end{array}$ & \multirow[t]{2}{*}{$\begin{array}{l}\text { Atividades desenvolvidas para crianças e } \\
\text { adultos, obedecendo as divisões já } \\
\text { existentes nos demais componentes de } \\
\text { ensino. }\end{array}$} \\
\hline & & & $\begin{array}{l}\text { EJA }- \text { Ensino } \\
\text { Fundamental }\left(1^{\mathrm{a}} \text { a } 4^{\mathrm{a}}\right. \\
\text { Séries })\end{array}$ & \\
\hline \multirow{3}{*}{ 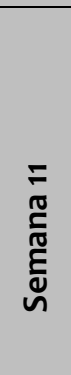 } & \multirow{3}{*}{ 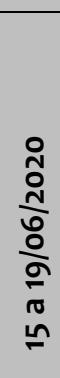 } & \multirow{3}{*}{$\begin{array}{l}\text { Línguas } \\
\text { Maternas } \\
\text { Indígenas } \\
\text { Macuxi e } \\
\text { Wapichana }\end{array}$} & $\begin{array}{l}1^{\circ} \text { e } 2^{\circ} \text { Períodos da } \\
\text { Educação Infantil }\end{array}$ & \multirow{3}{*}{$\begin{array}{l}\text { Atividades nas línguas maternas indígenas } \\
\text { para as crianças de } 04 \text { e } 05 \text { anos, } \\
\text { matriculadas no } 1^{\circ} \text { e } 2^{\circ} \text { Períodos da } \\
\text { Educação Infantil. Diferente das escolas } \\
\text { urbanas, nas indígenas o Ensino } \\
\text { Fundamental foi dividido apenas em } 02 \\
\text { (dois) grupos. }\end{array}$} \\
\hline & & & $\begin{array}{l}1^{\circ}, 2^{\circ} \text { e } 3^{\circ} \text { Anos do } \\
\text { Ensino Fundamental }\end{array}$ & \\
\hline & & & $\begin{array}{l}4^{\circ} \text { e } 5^{\circ} \text { Anos do Ensino } \\
\text { Fundamental }\end{array}$ & \\
\hline
\end{tabular}

Fonte: Elaborada pelas autoras, a partir das atividades do Projeto Aprendendo em casa BV, (2020)

Da análise do material não encontramos explicações sobre a variação de datas quanto a elaboração e disponibilização das atividades. Percebe-se desde o princípio os cuidados com os estudantes da educação especial e também com os componentes de ensino comuns à Base Nacional Comum Curricular - BNCC. Todavia, componentes de ensino como Artes e Educação Física só começaram a ser trabalhados depois de decorrido um mês de execução do referido projeto e as atividades em línguas maternas indígenas Macuxi e Wapichana, dois meses depois, o que denota que há sim diferenciação quanto as escolhas sobre o que e de que forma ensinar nas escolas da rede municipal de ensino de Boa Vista/RR, realizadas por meio da proposta do Projeto Aprendendo em Casa BV. 
Tabela 2 - Atividades desenvolvidas na Educação Especial - Deficiência Auditiva

\begin{tabular}{|c|c|c|c|}
\hline \multicolumn{3}{|c|}{ Dias da semana } & Assuntos e/ou abordagens \\
\hline \multirow{5}{*}{ 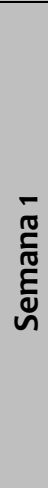 } & \multirow{5}{*}{ 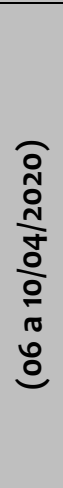 } & Segunda-feira & $\begin{array}{l}\text { Relembrar o alfabeto e manual e relacionar com imagem dentro do contexto } \\
\text { do aluno. }\end{array}$ \\
\hline & & Terça-feira & $\begin{array}{l}\text { Aprender sinais e expressões de sentimentos e/ou emoções, considerando o } \\
\text { contexto. }\end{array}$ \\
\hline & & Quarta-feira & Aprender sinais de objetos de casa de forma concreta e/ou leitura visual. \\
\hline & & Quinta-feira & Ampliar o vocabulário por meio da contação de história sinalizada. \\
\hline & & Sexta-feira & Conhecer sinais de cores e formas geométricas, de maneira lúdica. \\
\hline
\end{tabular}

Fonte: Elaborada pelas autoras, a partir das atividades do Projeto Aprendendo em Casa BV, (2020)

Em sua estreia o Projeto Aprendendo em Casa BV disponibilizou atividades aos discentes da Educação Especial e ainda trouxe atividades específicas para os estudantes com deficiência auditiva e deficientes visuais, com propostas de atividades a serem realizadas de segunda a sexta-feira, mas sem separação do material em relação a idade, ano ou modalidade de ensino, como ocorreu, posteriormente, com as atividades dos componentes de ensino comuns à BNCC. Nessa primeira semana as atividades destinadas aos discentes deficientes auditivos foi o manual e alfabeto na Língua Brasileira de Sinais LIBRAS, com o intuito de fortalecer e ampliar o vocabulário, léxico e conhecimento desses estudantes nessa língua, que para eles é fundamental.

Tabela 3 - Atividades desenvolvidas na Educação Infantil, com crianças de 02 a 05 anos de idade

\begin{tabular}{|c|c|c|c|}
\hline \multicolumn{3}{|c|}{ Dias da semana } & Assuntos e/ou abordagens \\
\hline \multirow{4}{*}{ 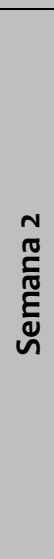 } & \multirow{4}{*}{ 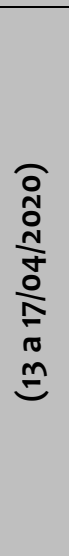 } & Segunda-feira & Atividades de audição e leitura da música do "Sítio do Pica Pau Amarelo". \\
\hline & & Terça-feira & Atividade de Movimento a partir da música do "Sítio do Pica Pau Amarelo". \\
\hline & & Quarta-feira & $\begin{array}{l}\text { Atividades de reciclagem - Boliche com garrafas PET; leitura da história dos } \\
\text { 'Três Porquinhos"; construção de fantoches com rolinho de papel ou } \\
\text { caixinhas; brincadeira de faz de conta; Construindo um circuito; construindo } \\
\text { casinha com lençol - brincadeira de faz de conta; leitura, audição, contação e } \\
\text { produção de história, a partir da história dos "Três Porquinhos". }\end{array}$ \\
\hline & & Quinta-feira & $\begin{array}{l}\text { Atividades de pintura - usando as mãos com tinta; reprodução da história "O } \\
\text { gato xadrez"; brincar de desenhar bigodes e nariz nos próprios rostos; }\end{array}$ \\
\hline
\end{tabular}




\begin{tabular}{|l|l|l|}
\hline & $\begin{array}{l}\text { criação de uma nova história e construção de um gato ou outro animal de } \\
\text { preferência da criança; Brincadeira do gato mia. }\end{array}$ \\
\cline { 2 - 3 } & Sexta-feira & $\begin{array}{l}\text { Brincando de adivinhar a partir da história do livro "João e o pé de feijão"; } \\
\text { sugestão de produção de um livrinho de histórias e um cantinho de leitura; } \\
\text { brincadeira com pinturas em pijamas; leitura e discussão sobre a história } \\
\text { "Viviana Rainha do Pijama". }\end{array}$ \\
\hline
\end{tabular}

Fonte: Elaborada pelas autoras, a partir das atividades do Projeto Aprendendo em Casa BV (2020)

A proposta de atividades do Projeto Aprendendo em Casa BV para a Educação Infantil, para crianças de 02 a 05 anos de idade, na segunda semana de execução do projeto, de 13 a 17 de abril de 2020 foi uma viagem pelo mundo das histórias infantis. E, conforme destacado no material:

As atividades pedagógicas descritas nesse documento foram pensadas com base na Proposta Municipal para a Educação Infantil, alinhada a Base Nacional Comum Curricular da Educação Infantil que trata-se de um documento legal que orienta quais aprendizagens as crianças precisam fazer na Educação Infantil, onde procurou-se garantir o direito de cada criança através das interações e brincadeiras realizadas nos ambientes familiares (RORAIMA, 2020, s/p.).

O documento no tópico da Educação Infantil enfatiza ainda que as atividades foram elaboradas em consonância e obediência aos direitos das crianças, citando como exemplo o direito ao convívio social e participação ativa entre adultos e crianças, garantindo também atividades de movimentos e brincadeiras, possibilitando que os infantes pudessem se expressar e "conhecer-se e construir sua identidade pessoal, social e cultural, constituindo uma imagem positiva de si e de seus grupos de pertencimento" (RORAIMA, 2020, s/p.). Todavia, todas essas atividades foram disponibilizadas apenas em Língua Portuguesa, desconsiderando a grande quantidade de estudantes imigrantes e também de indígenas nessa etapa da educação nas salas de aula da rede municipal de ensino de Boa Vista/RR.

Se a proposta realmente visasse e incentivasse a construção de identidade, com o fortalecimento dos grupos de pertença desses discentes, seria necessário que essas atividades fossem desenvolvidas na perspectiva de inclusão, com viés de interculturalidade, pois conforme assevera Fleuri: 
interpessoais imediatas - entender e promover lenta e prolongadamente a formação de contextos relacionais e coletivos de elaboração de significados que orientam a vida das pessoas (FLEURI, 2002, p.11).

Assim sendo, cabe aqui muitas indagações, dentre elas se as múltiplas diversidades existentes nas escolas da rede municipal de ensino estão sendo respeitadas na execução do referido projeto. $\mathrm{E}$, se há de fato a inclusão, como forma de direito de acesso e permanência desses discentes, bem como, se as escolas se inclinam a valorizar alguns conhecimentos em detrimento de outros? Continuaremos analisando esse material buscando responder essas inquietações.

Tabela 4 - Atividades desenvolvidas na Educação Física, com estudantes da Educação Infantil (04 e 05 anos), Ensino Fundamental ( $1^{\circ}$ ao $5^{\circ}$ ano $)$ e EJA (Ensino Fundamental - Anos Iniciais)

\begin{tabular}{|c|c|c|c|}
\hline \multicolumn{3}{|c|}{ Dias da semana } & Assuntos e/ou abordagens \\
\hline \multirow{5}{*}{ 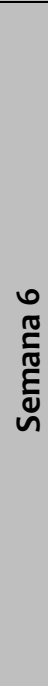 } & \multirow{5}{*}{ 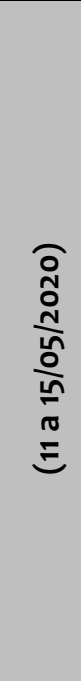 } & \multirow{5}{*}{ Sexta-feira } & $\begin{array}{l}\text { Exercícios físicos visando a queima de calorias - abdominais, polichinelos e } \\
\text { corrida parada. }\end{array}$ \\
\hline & & & Lateralidade - pegar a bolinha com rolamento lateral. \\
\hline & & & $\begin{array}{l}\text { Bola ao alvo (atividades de movimento), de forma a estimular a coordenação } \\
\text { motora ampla, cooperação, afetividade, atenção, concentração, muita } \\
\text { diversão. }\end{array}$ \\
\hline & & & $\begin{array}{l}\text { Alfabeto do exercício (Atividades de movimento), com a finalidade de } \\
\text { estimular os movimentos de forma coordenada, dominar o corpo de forma } \\
\text { capaz de vencer seus limites e promover o exercício físico em família. }\end{array}$ \\
\hline & & & $\begin{array}{l}\text { Desafio do copo, tendo como finalidade trabalhar a coordenação motora e } \\
\text { estimular a habilidade manual e a atenção. }\end{array}$ \\
\hline
\end{tabular}

Fonte: Elaborada pelas autoras, a partir das atividades do Projeto Aprendendo em Casa BV (2020)

A partir da $6^{a}$ semana do lançamento do Projeto Aprendendo em Casa BV, sempre às sextas-feiras, o projeto teve como enfoque de trabalho a Educação Física para os discentes da Educação Infantil, na faixa etária de 04 e 05 anos de idade, para aqueles que frequentam as aulas no Ensino Fundamental, de $1^{\circ}$ ao $5^{\circ}$ Ano e também para os alunos da Educação de Jovens e Adultos - Ensino Fundamental, anos iniciais, abordando temáticas como movimentos de forma coordenada, atividades físicas e os benefícios à saúde, hábitos saudáveis de alimentação, dentre outros. Nesse componente de conhecimento as atividades foram elaboradas partindo da parte teórica para a prática. 
Aqui, percebe-se novamente que nessas atividades e em todo o material, bem como vídeos com instruções e regras foram elaboradas apenas na língua portuguesa, caracterizando o caráter monocultural e o etnocêntrico que explícita ou implicitamente permeiam os afazeres pedagógicos e currículos escolares presentes nas escolas. Nesse sentido, ressalta-se que somente na segunda quinzena de junho, na $11^{\mathrm{a}}$ semana do projeto, houve a preocupação com os estudantes indígenas e a partir desse momento começa-se a elaboração e disseminação de atividades em línguas maternas Macuxi e Wapichana, também disponibilizadas via Instagram, por meio do perfil “@aprendendoemcasabv” e também enviadas pelos grupos do WhatsApp.

Conforme o material disponibilizado, em sua mensagem de apresentação consta que as atividades em línguas indígenas maternas foram elaboradas visando:

\begin{abstract}
Respeitar a identidade cultural e étnica dos alunos dos povos indígenas é um compromisso que o Projeto Aprendendo em Casa tem ao disponibilizar as atividades complementares de Língua Materna Macuxi, destinadas às crianças das Escolas Municipais Indígenas de Boa Vista. [...]. Ressaltamos que as atividades foram planejadas pelos professores de Língua Materna das escolas, e organizadas pela Coordenação das Escolas Indígenas e do Campo da SMEC - Macroárea 09, em consonância com os objetivos do Projeto Aprendendo em Casa (RORAIMA, 2020, s/p. Grifo nosso).
\end{abstract}

Naquela semana, mais precisamente na sexta-feira, dia 19/06/2020, o projeto propôs aos estudantes indígenas atividades abordando a valorização de sua cultura, por meio de músicas. No material, a proposta aos discentes de Língua Materna Macuxi foi a música “KANAWA RA'TÎPI”, que em língua portuguesa significa “A canoa virou” e aos de Língua Materna Wapichana, a música proposta foi “KAIMEM WA'AT KARY”, que em português significa “Bem Vindo".

Ainda segundo o material, essas atividades foram disponibilizadas também em meios digitais, como áudio e vídeo. Assim, a música "KANAWA RA'TîPI" foi distribuída:

Nos grupos de WhatsApp das escolas iremos encaminhar o VÍDEO dessa música nas Línguas Portuguesa e Macuxi, feito pela Professora Zeita Gregório, da Escola Municipal Indígena Tuxaua Albino Moraes, da Comunidade da Ilha (RORAIMA, 2020, s/p.).

E a música "KAIMEM WA'AT KARY”:

Nos grupos de WhatsApp das escolas iremos encaminhar os ÁUDIOS dessa música nas Línguas Portuguesa e Wapichana, feitos pelo Professor Adilson Gomes da 
Costa, da Escola Municipal Indígena Francisca Gomes da Silva, da Comunidade Serra do Truarú (RORAIMA, 2020, s/p.).

Da análise das atividades propostas pelo Projeto Aprendendo em Casa BV sob a ótica de numa perspectiva de inclusão, de interculturalidade, sem a sobreposição de uma cultura ou língua sobre a outra, dando ênfase à visão que privilegie as diferenças e respeito à diversidade é percebível que a proposta deve ser melhorada. Nas semanas iniciais, por exemplo, sentimos falta de atividades que privilegiassem as histórias de vida, memórias e culturas dos estudantes, e se assim o fosse, seria possível um diagnóstico balizador das futuras atividades. Nesse sentido, a produção de materiais didáticos deve proporcionar trocas e diálogos interculturais, onde as diferenças, no caso específico marcadamente linguísticos, sejam vistas como enriquecedoras e não como obstáculos.

Da continuidade da análise desse material verificou-se que nas semanas seguintes houve disponibilização de atividades nas línguas maternas Macuxi e Wapichana, todavia, devemos observar que esse material é denominado de "atividades complementares" e outro ponto a ser destacado é que essas atividades são disponibilizadas apenas nas sextasfeiras, assim como aquelas propostas para o componente Educação Física. De nossa leitura sobre o material, fica subtendido que as demais atividades disponibilizadas aos estudantes das escolas urbanas também estão à disposição daqueles das etnias Wapichana e Macuxi, nos mesmos formatos e também em língua portuguesa.

Cumpre-nos registrar que o projeto em tela foi paralisado em 18/12/2020 para o cumprimento do gozo de férias de docentes e discentes e conforme noticiado pelo G1 RR, em 15/01/2021 a "Prefeitura de Boa Vista aproveita atividades não obrigatórias para concluir ano letivo de 2020". Ou seja, o projeto que antes era distribuído para os estudantes com caráter apenas de atividades extracurriculares, não obrigatórias, passa com a aprovação do Parecer $n^{\circ}$ 17/2020 CME/BV/RR, de 31/12/2020 e publicado no DOM $n^{\circ}$ 5294, de 14/01/2021 a ter validade letiva, conforme disposto no ementário desse parecer:

Aproveitamento da carga horária das atividades não presenciais desenvolvidas por meio do Projeto Aprendendo em Casa BV, em período de Pandemia (COVID19), como forma de cumprimento da carga horária letiva relativa ao ano de 2020 (G1 RR, 2021, s/p.).

Se como atividades extracurriculares, como apoio aos estudantes durante o período de aulas não presenciais esse projeto já suscita muitos questionamentos devido 
ao seu caráter monolíngue em um contexto totalmente multicultural e multilinguístico e ainda em decorrência das muitas dificuldades de acesso por parte dos estudantes, que não receberam apoio institucional para a aquisição de meios digitais e tecnológicos e também de acesso à internet, necessários para acompanhar as atividades propostas, agora como instrumento de cômputo de carga horária e registro de frequência dos alunos gera mais dúvidas sobre sua execução e aplicabilidade, visto que diante das situações elencadas, é percebível que muitos estudantes foram deixados à margem nesse processo de ensino remoto.

\section{CONSIDERAÇÕES FINAIS}

Analisamos as atividades do Projeto Aprendendo em Casa BV até o mês de setembro, que à época estava em sua vigésima sexta semana de execução, com mais de 250 publicações em extensão PDF. Todavia, ressaltamos que o referido projeto continuou até 18/12/2020, sendo paralisado para o gozo de férias de professores da rede municipal de ensino de Boa Vista.

Durante todo o período de funcionamento o canal de disponibilização continuou sendo o perfil do “@aprendendoemcasabv" e também o site da PMBV, além dos muitos grupos de WhatsApp com interação diária entre professores, gestores e pais ou responsáveis por esses alunos, no envio e reenvio dessas atividades.

No tocante ao alcance, ao acesso desse material a PMBV em seu perfil do Instagram, em outubro de 2020 afirmara que já ultrapassava a marca de 20 (vinte) mil visualizações. Mas cabe a nós algumas reflexões e indagações. O estudante imigrante, com dificuldades de inserção em nossa sociedade tem conseguido acompanhar essas atividades em meios digitais e ainda em Língua Portuguesa? O aluno indígena tem acesso aos meios e ferramentas tecnológicas e internet para cumprir a contendo tais atividades estando nas zonas rurais de Boa Vista?

Em meio a todas essas dúvidas, destacamos que devemos olhar de forma mais inclusiva para esses discentes, visto que as atividades escritas ou faladas propostas no referido projeto foram elaboradas de forma monolíngue, imprimindo o caráter monocultural desse material. Há a exceção das “atividades complementares” em línguas 
indígenas maternas Macuxi e Wapichana. Dessa análise depreende-se que o projeto não demonstrou cuidado e zelo com as muitas diferenças e diversidades de nossos discentes. E, ainda, não atentaram para o fato de que as barreiras linguísticas podem desestimular aqueles que não dominam a língua falada e usada na escola, neste caso, a Língua Portuguesa e com isso exclui os estudantes imigrantes quer sejam indígenas ou não, bem como não inclui totalmente os indígenas brasileiros não falantes do português.

Evidenciamos ao longo desse trabalho a forma monolíngue, monocultural e etnocêntrica com que foram desenvolvidas as atividades do Projeto Aprendendo em Casa BV, mesmo com seu intuito primeiro de minimizar os impactos decorrentes da suspensão das aulas presenciais. Nosso questionamento tendo como fito a marginalização daqueles que não têm a Língua Portuguesa como língua materna e também devido a todas as dificuldades de acesso aos meios tecnológicos, digitais e de internet por parte desses discentes, que segundo Ferreira e Girardello (2019, p. 149) no tocante ao acesso à tecnologia "não garante que as crianças e os adolescentes tenham todas as proficiências necessárias". E, com a aprovação do Parecer n 17/2020 CME/BV/RR a exclusão desses alunos fica ainda mais explícita, pois a própria gestão municipal reconhece, conforme noticiado pelo $G 1 R^{12}$, que "[...] nem todos os alunos tiveram acesso às redes sociais para receber os conteúdos [...]", mesmo assim o município solicitou e o CME/BV/RR autorizou o aproveitamento das atividades do referido projeto para os estudantes de $1^{\circ}$ ao $5^{\circ}$ ano do Ensino Fundamental e também para os discentes de $1^{\mathrm{a}}$ a $4^{\mathrm{a}}$ série da Educação de Jovens e Adultos (EJA). Ainda segundo a matéria esse aproveitamento será de 50\% e 25\% para alunos do Ensino Fundamental e EJA, respectivamente.

Não deixaremos de registrar o lado positivo do referido projeto, no sentido de tentar minimizar os prejuízos devido a paralisação das aulas, em decorrência da Covid-19, que propôs aos discentes da rede municipal, por meios digitais e tecnológicos, atividades para que esses alunos não ficassem totalmente parados, sem nenhum acesso à educação nesse período pandêmico. Porém, é necessário questionar o alcance do projeto em questão, pois os problemas de acessibilidade por parte dos alunos ao material proposto

12 Ver mais em: https://g1.globo.com/rr/roraima/noticia/2021/01/15/prefeitura-de-boa-vista-aproveitaatividades-nao-obrigatorias-para-concluir-ano-letivo-de-2020.ghtml. Acesso em 29 mar. 2021. 
foram reconhecidos pelo próprio ente municipal. Sem contar que em relação à diversidade de línguas presentes nas salas de aulas da rede municipal de ensino é necessário que se repense as estratégias desse material, de forma a incluir em todo e qualquer processo educativo as crianças brasileiras e imigrantes, indígenas ou não indígenas, visto que as diferenças, sobretudo linguísticas não devem ser vistas nem tratadas como esquisitas ou deslocadas e sim que se privilegie a pluralidade de línguas e culturas sem o prejulgamento e a sobreposição de uma sobre as outras. Assim, destacamos que faltou um olhar mais cuidado e zeloso no tocante à heterogeneidade cultural e linguística de nossas escolas. Vale salientar que essa proposta, ainda vigente na rede municipal, carece de adaptações visando incluir todos os estudantes independentemente de serem brasileiros, estrangeiros ou indígenas, de forma a garantir o acesso ao conhecimento de forma plural.

\section{REFERÊNCIAS}

AMADO, Roseane de Sá. O português como língua de acolhimento para refugiados. Revista da SIPLE. Brasília, ano 4, n. 2, out. 2013. [online]. Disponível em: $<$ http://www.siple.org.br/index.php?option=com_content\&view=article\&id=309:0-ensinode-portugues-como-lingua-de-acolhimento-para-refugiados\&catid=70:edicao-

7\&ltemid=113>. Acesso em: 18 ago. 2020.

BEHAR, Patricia Alejandra. O ensino remoto emergencial e a Educação a Distância. [online]. Disponível em https://www.ufrgs.br/coronavirus/base/artigo-o-ensino-/remotoemergencial-e-a-educacao-a-distancia/. Acesso em 20 out. 2020.

BRASIL. Lei $\mathbf{n}^{\circ} \mathbf{1 1 . 6 4 5}$, de 10 de março de 2008. Disponível em http://www.planalto.gov.br. Acesso em: 05 out. 2020.

BRASIL. Decreto ${ }^{\circ}$ 5.622, de 19 de dezembro de 2005 - Regulamenta o art. 80 da Lei $n^{\circ}$ 9.394, de 20 de dezembro de 1996, que estabelece as diretrizes e bases da educação nacional. Disponível em: https://www2.camara.leg.br/legin/fed/decret/2005/decreto-562219-dezembro-2005-539654-publicacaooriginal-39018-pe.html. Acesso em: 24 out. 2020.

BRASIL. MINISTÉRIO DA EDUCAÇÃO. Parecer CNE/CP $\mathrm{n}^{\circ}$ 05/2020. Disponível em: http://portal.mec.gov.br/index.php?option=com_docman\&view=download\&alias=145011pcp005-20\&category_slug=marco-2020-pdf\&ltemid=30192. Acesso em: 05 out. 2020.

CANDAU, Vera Maria Ferrão. Educação intercultural e cotidiano escolar. Rio de Janeiro: 7Letras, 2002. p. 53. 
Revista do Programa de Pós-Graduação em Educação da Unochapecó ISSN 1984-1566 (on-line) ISSN 1415-8175 (impressa)

CESUSC. Veja a diferença entre EAD e aulas remotas. 2020. Disponível em: https://www.cesusc.edu.br/veja-diferenca-entre-ead-e-aulas-remotas. Acesso em: 15 out. 2020.

CHAVES, Ceiça @aprendendoemcasabv: ambiente virtual vira sala de aula em tempos de pandemia. Roraima em Foco, Roraima. 19 out. 2020. Variedades. Disponível em: https://roraimaemfoco.com.br/acervo/tag/ambiente-virtual/.Acesso em: 20 out. 2020.

DINIZ, Leandro Rodrigues Alves; NEVES, Amélia de Oliveira. Políticas linguísticas de (in)visibilização de estudantes imigrantes e refugiados no ensino básico brasileiro. Revista X, v. 13, n. 1, p. 87-110, 2018. https://doi.org/10.5380/rvx.v13i1.61225. Acesso em: 12 mai. 2021

FERREIRA, Viviane Lima; GIRARDELLO, Gilka Elvira Ponzi. Um olhar intercultural para a Mídia-Educação: diferenças e desigualdade nos contextos de acesso às mídias. Revista Pedagógica, Chapecó, v. 21, p. 131-153, 2019. DOI: http://dx.doi.org/10.22196/rp.v21io.4781. Acesso em: 19 abr. 2021.

FLEURI, Reinaldo Matias. Intercultura e educação. Revista Brasileira de Educação, n. 23, p. 16-35, 2003.

HODGES, Charles et. al. Diferenças entre o aprendizado online e o ensino remoto de emergência. Revista da Escola, Professor, Educação e Tecnologia. Disponível em: https://escribo.com/revista/index.php/escola/article/view/17/16. Acesso em: 15 out. 2020.

MARCONI, Marina de Andrade; LAKATOS, Eva Maria. Fundamentos de metodologia científica. 5. ed. Paulo: Atlas, 2003.

MINAYO, Maria Cecília de Souza. (Org). Pesquisa Social: teoria, método e criatividade. Petrópolis: Vozes, 1995.

RORAIMA. Decreto Municipal $\mathbf{n}^{\circ}$ 033-E/2020 - Dispõe sobre a adoção, no âmbito da Administração Pública direta e indireta, de medidas temporárias e emergenciais de prevenção de contágio pela Covid-19 (Novo Coronavírus), bem como sobre recomendações no setor privado municipal. Diário Oficial do Município de Boa Vista, Edição n’ 5089. Disponível em: https://www.boavista.rr.gov.br/diario-oficial. Acesso em: 28 jul. 2020.

RORAIMA. Projeto Aprendendo em Casa BV. Disponível em: https://observatorio.prefeitura.boavista.br/paginas/aprendendo-em-casa-bv. Acesso em: 28 jul. 2020.

SÃO BERNARDO, Mirelle Amaral de. Português como língua de acolhimento: um estudo com imigrantes e pessoas em situação de refúgio no Brasil. 2016, 206F. Tese de Doutorado. Programa de Pós-graduação em Linguística, Universidade Federal de São Carlos, 2016. 
Revista do Programa de Pós-Graduação em Educação da Unochapecó ISSN 1984-1566 (on-line) ISSN 1415-8175 (impressa)

SILVA, Marcus Vinícius; ZAMBRANO, Cora Elena Gonzalo. Do global ao local no ensino de PLAC em RORAIMA: por uma formação de histórias locais na Universidade Federal de Roraima. Linguagem \& Ensino, v. 24, p. 207-225, 2021. Disponível em: https://periodicos.ufpel.edu.br/ojs2/index.php/rle/article/view/19276. Acesso em: 14 mai. 2021.

THURCK, Ádini Leite Nunes. As visões de língua, sujeito e sala de aula de professores de língua inglesa. Revista Intercâmbio, v. XXIV: 1-12, 2011. São Paulo: LAEL/PUCSP. ISSN 2237759x.

ZAJAC, Danilo. Ensino remoto na Educação Básica e COVID-19: um agravo ao Direito à Educação e outros impasses. Disponível em: http://proec.ufabc.edu.br/epufabc/ensinoremoto-na-educacao-basica/. Acesso em: 15 out. 2020.

ZAMBRANO, Cora Elena Gonzalo. Español como lengua de migración en Roraima y las nuevas políticas lingüísticas horizontales y verticales. In: Congresso Brasileiro de Hispanistas. Anais XI Congresso Brasileiro de Hispanistas, Campina Grande: Realize Editora, 2020. Disponível em: https://editorarealize.com.br/artigo/visualizar/72670. Acesso em: 05 jan. 2021.

Recebido em: 21-04-2021

Aprovado em: 12-05-2021

Publicado em: 26-05-2021 